https:/ / doi.org/10.18485/iipe_nsail.2020.ch5

Sanja JELISAVAC TROŠIĆ ${ }^{1}$

\title{
MULTINACIONALNE KOMPANIJE U MEĐUNARODNOM PRAVU
}

Apstrakt: Veoma važnu ulogu u svetskoj privredi danas imaju multinacionalne kompanije (MNK), koje po svojoj prirodi nastaju udruživanjem kapitala radi sticanja što većeg profita. Kada se govori o globalizaciji i integraciji poslovanja na svetskom tržištu oni se ne mogu zamisliti bez MNK, koje su ujedno i posledica i pokretač ovih procesa. Ove kompanije ostvaruju veliki profit, a njihovo poslovanje prevazilazi nacionalne granice i nacionalne propise. MNK svojim delovanjem dovode do usložnjavanja ekonomskih i pravnih odnosa i njihove regulative. Pojedine MNK se u svetskoj privredi i u međunarodnom pravu pojavljuju kao izrazito moćni nedržavni akteri. S obzirom na to da su neke MNK čak ekonomski snažnije nego mnoge države sveta, one nastoje da od država putem uspostavljanja međusobnih odnosa, kao i putem drugih pravnih regulativa dobiju brojne ustupke. Takođe, one u cilju sticanja što veće dobiti, usmeravaju i vrše uticaj i na rad međunarodnih organizacija. Na taj način MNK su trenutno jedan od najmoćnijih subjekta savremenih međunarodnih ekonomskih odnosa, a tu poziciju nastoje da steknu i u pravnoj sferi. Cilj ovog rada je istražiti položaj MNK u međunarodnoj zajednici i posebno međunarodnom pravu, kao i problematiku međunarodnog pravnog regulisanja MNK, kršenje međunarodnog prava i okvire za njihovu odgovornost, kao i elemente međunarodnog pravnog subjektiviteta.

Ključne reči: Multinacionalne kompanije, MNK, transnacionalne kompanije, kapital, filijale, međunarodno pravo, međunarodnopravni subjektivitet, međunarodnopravno regulisanje, ljudska prava.

${ }^{1}$ Viši naučni saradnik, Institut za međunarodnu politiku i privredu, Beograd, e-mail: sanja@diplomacy.bg.ac.rs.

Rad je nastao u okviru naučnoistraživačkog projekta "Srbija i izazovi u međunarodnim odnosima 2020. godine", koji finansira Ministarstvo prosvete, nauke i tehnološkog razvoja Republike Srbije, a realizuje Institut za međunarodnu politiku i privredu tokom 2020. godine. 


\section{UVOD}

Sa protokom vremena poslovanje pojedinih preduzeća postajalo je veće od potreba domaćeg tržišta, tako su se javile potrebe za proširenjem tržišta i izlaskom iz nacionalnih okvira. Osnivanje filijala u inostranstvu od strane preduzeća koja su svojim rastom, proizvodnjom i plasmanom prevazišla potrebe domaćeg tržišta, bio je način da se zaobiđu brojna ograničenja u poslovanju na inostranom tržištu.

Sa smanjivanjem i uklanjanjem barijera u međunarodnoj trgovini, kao i olakšavanjem protoka investicija, otvoren je i olakšan put ka jačanju multinacionalnih kompanija (MNK). Tehnološki napredak i savremene komunikacije, uz snižavanje troškova prevoza i formiranje globalnih lanaca vrednosti, takođe su doprineli širenju uticaja i obima poslovanja MNK. Tokom poslednjih nekoliko decenija MNK su postali lideri promena u globalnoj ekonomiji.

U literaturi, medijima i u praksi najčešće se ne pravi razlika između transnacionalne i multinacionalne kompanije. Mi ćemo $\mathrm{u}$ ovom radu najčešće koristiti termin multinacionalna kompanija - MNK, ali radi pojašnjenja napominjemo da je najveća razlika (pored brojnih sličnosti) između ova dva pojma $u$ tome što se rukovodstvo multinacionalne kompanije nalazi u više zemalja, tako da matična zemlja (zemlja porekla) ove kompanije nije samo jedna zemlja, već je to veći broj zemalja, dok je transnacionalna kompanija svaka ona kompanija koja ima ili kontrolise proizvodne ili uslužne pogone van svoje zemlje.

U svetu ne postoji jedinstvena terminologija. Svoje definicije multinacionalnih kompanija, odnosno transnacionalnih kompanija, daju razne međunarodne organizacije, kao i one koje statistički prate i proucavaju aktivnosti ovih kompanija u svetskoj privredi (OECD, MMF, Svetska banka, UN i druge). Organizacija Ujedinjenih nacija koristi termin transnacionalna korporacija (transnational corporation), dok OECD i ILO koriste termin multinacionalno preduzeće (multinational enterprise), na primer.

Ono što MNK, pre svega, izdvaja u odnosu na klasična preduzeća je to što one raspolažu sa ogromnim kapitalom, filijalama u velikom broju država (preduzeća ćerke), velikim brojem zaposlenih iz različitih država 
i drugo. Kada pominjemo MNK mislimo na, u svakom smislu, moćne i velike kompanije, moćne kako po ekonomskim tako i po drugim parametrima uticaja. Ove kompanije se mogu naći u različitim sektorima poslovanja - od banaka, grupa hotela, građevinskih kompanija, preko najmodernijih IT kompanija. Često, mada to nije u slučaju svih, MNK imaju proizvode i usluge sa visokim udelom istraživanja i razvoja $u$ strukturi troškova proizvodnje. To je posebno slučaj u MNK iz domena računarskih tehnologija i farmaceutskih proizvoda. U ovako troškovno zahtevnim oblastima poslovanja, gde su velika početna ulaganja $u$ istraživanje i razvoj, a gde je dugačak i neizvestan vremenski period do tržišno isplativog proizvoda, posebno se ističe prednost MNK da obezbede velika početna finansijska sredstva.

Interesantno je pomenuti da se prema klasičnom statističkom obračunu spoljnotrgovinskih tokova dolazi do velikog broja slučajeva da filijale MNK proizvode tehnološki intenzivne proizvode, koji imaju višu dodatu vrednost, pa samim tim i višu prodajnu cenu, dok se njihov izvoz statistički pripisuje zemlji domaćinu te filijale, a ne zemlji matici.

\section{PROBLEMATIKA STATISTIČKOG OBUHVATA MULTINACIONALNIH KOMPANIJA}

Kompanije u visoko industrijalizovanim zemljama su posle početnih godina širenja obima proizvodnje i proširivanja tržišta na međunarodne okvire, kroz tržišnu utakmicu na svetskom nivou, shvatile isplativost preseljenja svojih industrijskih pogona u manje razvijene zemlje, zbog prednosti korišćenja jeftinijih resursa i manje strogih ekoloških propisa. Na taj način su mnogi industrijski pogoni iz razvijenih zemalja preseljeni $\mathrm{u}$ zemlje $\mathrm{u}$ razvoju i $\mathrm{u}$ nerazvijene zemlje. Nosioci ovog procesa, tzv. deindustrijalizacije razvijenih zemalja, odnosno seljenja čitavih industrijskih pogona iz razvijenih zemalja u zemlje sa manjim troškovima proizvodnje su upravo multinacionalne i transnacionalne kompanije. Na ovaj način kompanije optimizuju troškove svoje proizvodnje na svetskom nivou. Uprošćeno opisano - ceo proces izgleda ovako: sirovine se vade $u$ najčešće najnerazvijenijim zemljama sveta, prerađuju se u zemljama gde su jeftini troškovi radne snage i slaba 
ekološka zaštita, poluproizvodi se razmenjuju između filijala preduzeća (koje su u različitim zemljama), sklapaju se ili se prerađuju do finalnog proizvoda, najčešće blizu velikih i propulzivnih tržišta, tj. razvijenih zemalja na čijim tržištima će se oni prodati.

Razumevanje snage, uticaja i položaja multinacionalnih kompanija, kako rade i gde placaju porez presudno je za dobru pravnu regulativu i kreiranje politika država u kojima one obavljaju svoje poslovanje. Međutim, u svetu je malo zvaničnih statističkih podataka o pojedinačnim MNK. Dobru makroekonomsku statistiku, koja bi bila dobra osnova za pravnu regulativu na međunarodnom nivou, trenutno je teško pronaći, pa je OECD počeo da razvija novu bazu podataka - Analitičku bazu podataka o pojedinim multinacionalnim kompanijama i pridruženim partnerima (ADIMA). Ova baza radi koristeći brojne otvorene velike izvore podataka koji mogu pružiti nove uvide o pojedinim MNK i njihovim globalnim profilima. Prema pomenutoj ADIMA bazi, 100 obuhvaćenih multinacionalnih kompanija je 2016. godine prihodovalo skoro 10 biliona dolara, što je gotovo $20 \%$ globalnog bruto domaćeg proizvoda (BDP). Na iste MNK se odnosi i zarada od 730 milijardi dolara, kao i plaćenih 185 milijardi dolara poreza (pogledati sliku 1). ${ }^{2}$ 
Slika 1: Disperzija efektivnih poreskih stopa za ADIMA-100

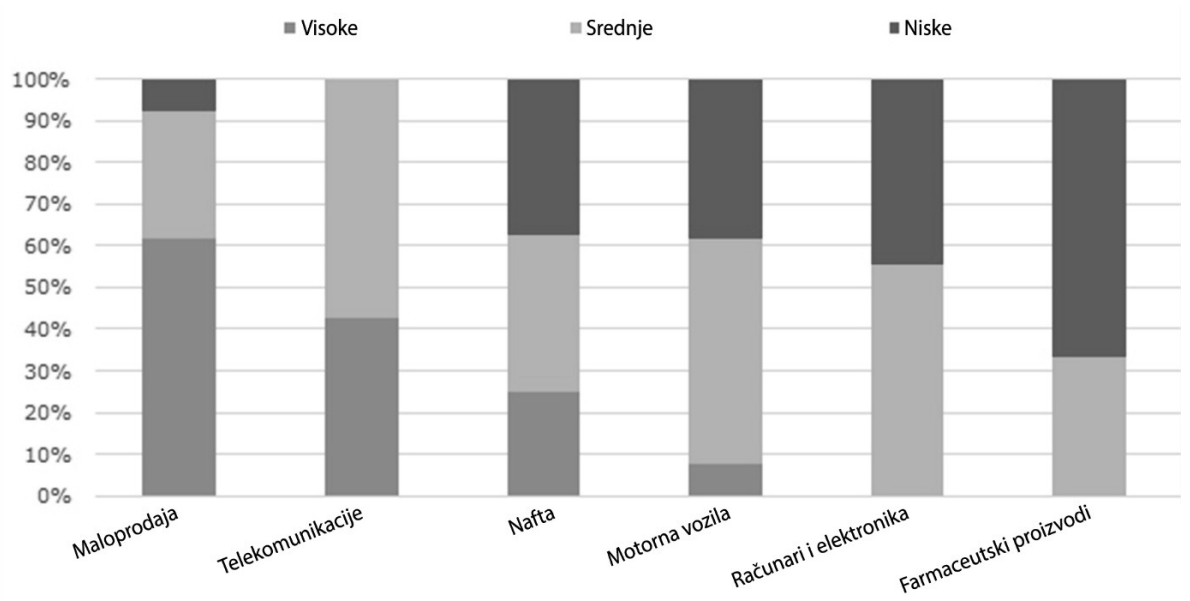

Napomena: Niske - odnosi se na efektivne poreske stope ispod $23 \%$, srednje - na efektivne poreske stope između $23 \%$ i 33\%, i visoke na efektivne poreske stope iznad $33 \%$. Ovakve vrednosti su izabrane tako da je trećina populacije ADIMA-100 bila prisutna u svakoj klasifikaciji.

Izvor: OECD baza podataka ADIMA

Dodatne informacije, koje je pomoću statističkog praćenja u ADIMA bazi bilo moguće utvrditi, pokazuju da iako je prema godišnjim izveštajima kompanija od posmatranih $100 \mathrm{MNK}$ njih 74 fizički prisutno u Velikoj Britaniji, njihov stvarni broj je 85. Dodatnih 11 MNK je identifikovano pomoću komplementarnih izvora, npr. identifikatora pravne osobe, veb lokacije i slično.

Interesantan je i nalaz da fizička prisutnost ne odražava digitalnu prisutnost, što se posebno vidi kod kompanija čiji je jedini prodor na različita tržišta putem veb lokacija specifičnih za zemlju (znači nema fizičkog prisustva). Ovo je posebno važno za statistiku o visoko digitalizovanim MNK, jer pružanje digitalizovanih usluga zamagljuje tradicionalnu liniju između kompanija sa stranim prisustvom i

${ }^{2}$ OECD, Baza ADIMA, https://www.oecd.org/sdd/its/measuring-multinationalenterprises.htm, 13.06.2020. 
kompanija koje trguju preko granice, što može uticati na uporedivost međunarodnih podataka o trgovini i nacionalnom dohotku.

Istraživanjem ove beze dolazimo i do podataka o različitosti online i fizičkih filijala, posebno što se broj svakim danom povećava u korist prvih. ADIMA digitalni registar obuhvata 20.000 veb lokacija, dok ADIMA fizički registar obuhvata 26.000 filijala. U manjim zemljama je digitalno prisustvo često čak i važnije: na primer, samo 10 od ADIMA100 fizički je prisutno u Estoniji, ali još 19 uglavnom digitalnih kompanija ima elektronsko prisustvo (pogledati sliku 2). ${ }^{3}$

Slika 2: Pokrivenost MNK u OECD zemljama prema izvorima od strane ADIMA-100

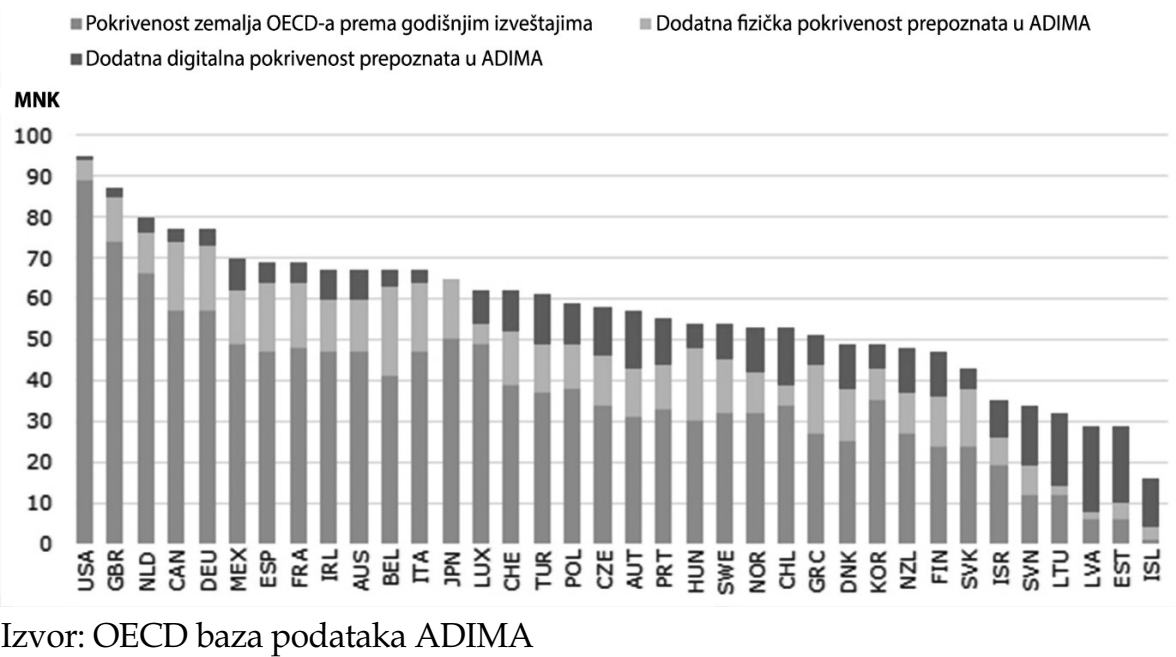

Možemo uočiti još jedan zanimljiv primer - godišnji izveštaji za Alphabet, Guglovu (Google) matičnu kompaniju, pokazuju filijale u dve zemlje OECD-a, ali fizički i digitalni registri ADIMA-e beleže filijale i/ili nacionalne veb stranice u svim zemljama OECD-a. Za bilo koji naziv domena, prihod od oglašavanja može se evidentirati kao domaća ili kao

${ }^{3}$ Ibidem 
prekogranična transakcija. Izbor može zavisiti i od toga da li je lokacija specifična za tu zemlju legalno registrovana u toj zemlji. ${ }^{4}$ Samo i prema ovde iznetim primerima vidimo da postoji veliki broj dilema koje treba rešiti u statističkom obuhvatu multinacionalnih kompanija, kao i njihovoj pravnoj regulativi. Deo rešavanja obuhvatnosti i tumačenja svih transakcija multinacionalnih kompanija počeo je da obavlja OECD sa svojom ADIMA bazom, pa će se već u bližoj budućnosti moći proveriti uspešnost ovakvog pristupa.

\section{SNAGA MULTINACIONALNIH KOMPANIJA U MEĐUNARODNIM OKVIRIMA}

Multinacionalna kompanija može stvarati tehničko znanje na jednoj lokaciji, bez obzira da li je to matica ili filijala, a koristiti ga u više proizvodnih pogona u raznim zemljama. MNK na taj način rasprostiru troškove istraživanja, tehničkog razvoja i marketinga na sve filijale. Prednost za MNK se ogleda u tome što u slučaju dve nezavisne firme, svaka mora pojedinačno da pravi ove iste troškove, pa u startu imaju veće ukupne troškove. MNK su najveći davaoci investicija baziranih na znanju, uključujući tu i tehnologiju, inženjering, menadžment, marketing i finansijske usluge. Ove kompanije takođe prodaju prava na znanje, uključujući tu patente, žigove, poslovne tajne i autorska prava. ${ }^{5} \mathrm{Na}$ taj način prava intelektualne svojine utiču na investicione tokove i operacije multinacionalnih kompanija. Strane direktne investicije za MNK su posebno važne, jer su multinacionalne kompanije ujedno i izvor kapitala i izvor znanja o proizvodnim tehnikama.

Politika sve veće otvorenosti zemalja $u$ tranziciji, i uopšte zemalja $u$ razvoju, za strane investicije i za puštanje MNK na domaće tržište, može se sagledavati sa stanovišta konkretnih rezultata u samim tim državama. Investicije koje podstiču razvoj domaće privrede, pogotovo njenih najmodernijih grana, zaista pozitivno doprinose celokupnom društvenom

\footnotetext{
${ }^{4}$ Ibidem

${ }^{5}$ Sanja Jelisavac, Intelektualna svojina - međunarodna trgovina pravima intelektualne svojine, Institut za međunarodnu politiku i privredu, Beograd, 2006, str. 62.
} 
razvoju zemlje koja prima te strane investitore i jasno je da su one neophodne zemljama u tranziciji koje žele da podignu svoj razvoj na viši nivo. Kupovinom domaćih preduzeća moćne strane MNK u svakom slučaju povećavaju njihovu efikasnost. Ali, to ima i drugu stranu, jer povećana efikasnost preduzeća, koje je prešlo u strano vlasništvo, ne podrazumeva samo po sebi povećanje efikasnosti celokupne nacionalne privrede konkretne zemlje, jer proizvodnja i zaposlenost se brzo smanjuju u domaćim preduzećima, doskora povezanih proizvodnim lancem sa preduzećem koje se sada nalazi u stranom vlasništvu. Umesto sa domaćim, ono se povezuje sa filijalama multinacionalne kompanije u čijoj je svojini, a kupovna moć zaposlenih u njemu usmerava se sa potrošnje domaćih na potrošnju uvoznih dobara. Prema tome, neposredne strane investicije MNK nisu univerzalni lek za makroekonomske probleme zemalja, što pokazuju i podaci o tim investicijama, tekućim primanjima, zaduženosti i privrednom rastu osam kandidata za ulazak u Evropsku uniju u poslednjih deset godina. ${ }^{6}$

Poslovanje MNK ima izrazit uticaj i na kretanje obima međunarodne trgovine. Prvi put kada je Kina pretekla SAD, kao najznačajniji svetski izvoznik industrijskih proizvoda, bilo je zbog seljenja kapitala multinacionalnih kompanija iz SAD-a u Kinu. Naime, američke kompanije su u svojim kineskim filijalama organizovale proizvodnju (made in China). Na taj način Kina je postala zemlja koja proizvodi skoro sve za ceo svet. To je uzelo toliko maha da je deo izvoza iz slobodnih proizvodnih zona iz Kine, u ukupnom izvozu Kine, iznosio čak 50\%, prema podacima Svetske trgovinske organizacije za 2007. godinu. ${ }^{7}$

\section{PROBLEMATIKA MEĐUNARODNOG PRAVNOG REGULISANJA MULTINACIONALNIH KOMPANIJA}

MNK u međunarodnoj ekonomiji zauzimaju sve češće vodeće uloge, na nivou čak i uloga država, dok je u međunarodnom pravu njihovo

\footnotetext{
${ }^{6}$ Sanja Jelisavac Trošić, Pregovori u okviru GATT i STO, Institut za međunarodnu politiku i privredu, Beograd, 2015, str. 279-280.

${ }^{7}$ Bjelić Predrag, Sanja Jelisavac Trošić, Ivana Popović Petrović, Savremena međunarodna trgovina, Institut za međunarodnu politiku i privredu, Beograd, 2010, str. 124.
} 
mesto još uvek upitno jer države za sada i dalje tu imaju glavnu ulogu. Multinacionalne kompanije u cilju stvaranja što većeg profita obavljaju poslovanje $u$ više zemalja. MNK se ne osnivaju međunarodnim ugovorom i ne funkcionišu po međunarodnom pravu dok su, s druge strane, u stanju da sklapaju ugovore sa državama na koje se primenjuju opšta pravila međunarodnog prava. Sklapajući ugovore, MNK stvaraju praksu koja s vremenom prerasta u običaj, ali i dalje ne stvara međunarodno pravo.

Prema međunarodnom javnom pravu, MNK se smatraju nedržavnim akterima koji se definišu činjenicom da im nedostaju jedna ili više karakteristika države. Međunarodno pravni status MNK nije još uvek jasan, najviše zbog toga što je i dalje u toku njegov razvoj. Opšte je prihvaćeno da nedržavni akteri, $u$ ovom slučaju multinacionalne kompanije, imaju određeni stepen pravne ličnosti u međunarodnom pravu. Međutim, o preciznom obimu se mnogo raspravlja i obično se vidi da je prilično ograničen, sigurno mnogo uže od međunarodnih organizacija. Ovo ostavlja MNK u komplikovanom položaju u odnosu na međunarodno pravo, jer međunarodna pravila postoje u korist MNK, ali da li prenose prava na MNK? U tom pogledu, MNK imaju međunarodni pravni status koji je čudno sličan statusu životinja koje su zaštićene zakonom, ali ne mogu preduzeti nezavisne radnje da bi zatražile takvu zaštitu. One se obično moraju oslanjati na države kako bi osigurale da imaju koristi od pravila, ali ne mogu u potpunosti i nezavisno učestvovati $u$ međunarodnim institucijama kao što je na primer Svetska trgovinska organizacija. Međutim, postoje i drugi slučajevi - MNK se mogu samostalno pojavljivati i predstavljati u Međunarodnom centru za rešavanje investicionih sporova (ICSID) i Sporazumu između SAD, Kanade i Meksika (USMCA bivša NAFTA). ${ }^{8}$ Prema tome, postoje određeni tokovi i tendencije da se tretiranje, multinacionalnih kompanija u međunarodnom pravu približava položaju, tretmanu i funkcijama države.

\footnotetext{
${ }^{8}$ Malanczuk Sornarajah, "Sources of international law in foreign investment" in The international law on foreign investment, Cambridge: Cambridge University Press, 2010, pp. 79-87.
} 
Pojedini autori tvrde da bi MNK, poput na primer međunarodnih organizacija, pravilnije trebalo posmatrati kao „učesnike" u međunarodnom pravu, a ne postavljati pitanje da li su one ",subjekti“ međunarodnog prava. ${ }^{9}$ Tri su kriterijuma za utvrđivanje nacionalnosti preduzeća:

1) inkorporisanje,

2) sedište, $i$

3) kontrola.

Prema prvom kriterijumu kompanija dobija nacionalnost one jurisdikcije koja ga je osnovala. Prema drugom kriterijumu nacionalnost se određuje prema sedištu, odnosno zakonu mesta u kojem se nalazi uprava. Prema trećem kriterijumu za nacionalnost kompanije uzima se mesto na kome se nalazi stvarni centar odlučivanja, centar koji odlučuje o strategiji poslovanja i centar finansijskog upravljanja preduzećem. ${ }^{10}$

MNK je kompanija koja je osnovana u više od jedne nacionalne države, ali se njom upravlja najčešće iz jednog centra. Tipična MNK sastoji se od matične kompanije (preduzeće majka) u jednoj državi, sa podružnicama $u$ jednoj ili više drugih država. ${ }^{11}$ Poslovanje MNK se, naravno, prilagođava određenim zakonima, politikama, običajima, željama potrošača i mnogim drugim faktorima. Za ove kompanije i njihov rad može se navesti mnogo toga i dobrog i lošeg. Stremeći svojim ciljevima umnožavanja profita, MNK prilagođava svoje poslovanje zakonodavnom okviru. Osnivanje svake filijale pojedinačno predstavlja ulazak na teritoriju i zakonsku regulativu strane zemlje. Međutim, ta filijala je i dalje kapitalno i poslovno zavisna od svoje matice. Na ovaj način sam sistem funkcionisanja MNK omogućava da može koristiti, za određenu poslovnu operaciju, upravo onu filijalu koja je u zemlji sa najpovoljnijim pravnim poretkom za taj posao. Znači, upravo razlika u pravnoj regulativi različitih zemalja u kojima matična kompanija ima

\footnotetext{
${ }^{9}$ José Alvarez, 2010 “Are Corporations 'Subjects' of International Law?' " NYU School of Law, Public Law Research Paper No. 10-77, Available at SSRN: http:/ / ssrn.com/abstract=1703465, 26.05.2020.

${ }^{10}$ Miodrag Sukijasović, Multinacionalno preduzeće - pravni aspekti, Institut za međunarodnu politiku i privredu, Beograd 1981, str. 47-48.

${ }^{11}$ U literaturi se podjednako koriste termini podružnice, preduzeća ćerke ili filijale.
} 
svoje filijale, omogućavaju joj izvlačenje koristi od pravnih regulativa. Mogući su slučajevi, da u cilju smanjivanja troškova poslovanja, preduzeće matica donese odluku koju filijala mora sprovoditi, iako ona može doneti štetu i zemlji domaćinu i samoj filijali. Na ovaj način je jasno da su ne samo mogući nego i izvesni sukobi interesa između zemlje domaćina filijala i matične multinacionalne kompanije. To dovodi do sukoba ekonomske moći MNK sa suverenošću zemalja u kojima se nalaze filijale.

Najveći problem sa pravnim regulisanjem MNK, između ostalog i sa njihovim statističkim praćenjem, proizilazi baš iz njihove prirode multinacionalnosti. To je nedostatak regulative u međunarodnom pravu, što dovodi do nedostatka njihove međunarodne odgovornosti. Svaka zemlja pojedinačno kreira izvore prava koji se odnose na poslovanje i delatnost multinacionalnih kompanija. U tradicionalnom pravu, MNK imaju svoja prava ali nemaju obaveze, što bilo kome ko je oštećen - da li je to država ili neko drugo preduzeće ili pojedinac - stvara veliki problem. U praksi se najčešće dešava da se države, između ostalog, međusobno takmiče da svojim propisima, odnosno da svojom pravnom regulativom privuku strani kapital u zemlju. Regulatorni okvir država, primenljiv na priliv kapitala odnosno investicije multinacionalnih kompanija, zato ima tendenciju da slabi a ne naprotiv da jača. Na taj način, u praksi, MNK podležu samo sve slabijim domaćim zakonima država u kojima posluju. Sa uvećavanjem kapitala, lobiranja i političke moći ovih kompanija, postaje sve jasnije da je univerzalna međunarodna pravna regulativa, koja će i obavezati na poštovanje nekog minimuma pravnih normi, i više nego potrebna.

Sa druge strane, primer da MNK još odavno traže način da institucionalno i na međunarodnom nivou zaštite svoja prava i interese možemo uočiti kod Deklaracije OECD o međunarodnim investicionim i multinacionalnim kompanijama. Ovu Deklaraciju prvi put su usvojile vlade zemalja članica OECD-a 21. juna 1976. godine i od tada je u više navrata revidirana $\left(1979,1984,1991,2000\right.$. i 2011). ${ }^{12}$ Deklaracijom se želelo

${ }^{12} \mathrm{OECD}$, "Declaration on International Investment and Multinational Enterprises", https://legalinstruments.oecd.org/en/instruments/OECD-LEGAL-0144, 02.04.2020. 
stvoriti otvoreno i transparentno okruženje za međunarodna ulaganja, tako da ona sadrži obaveze vlada da obezbede nacionalni tretman za kompanije koje su pod kontrolom stranih lica, da se izbegnu sukobljeni zahtevi prema preduzećima i da se sarađuje u vezi sa podsticajima i preprekama kod ulaganja. Svaki taj elemenat je podržan pravno obavezujućom Odlukom o postupcima praćenja. Obavezu da će se pridržavati odredbi OECD Deklaracije potvrdilo je 49 zemalja, od kojih 12 nisu zemlje članice OECD-a.

Samom prirodom svoje moći i poslovanja MNK nastoje da ostvare monopol na svakom tržištu na kojem posluju. MNK svoju moć koriste lobirajući u matičnim ali i u državama svojih filijala, učestvujući u pregovorima na državnom ali i u međunarodnim okvirima utiču na formulisanje međunarodnih ugovora. MNK već učestvuju na ravnopravnoj osnovi u pregovorima sa državama, negde čak i sa jačim pozicijama i uticajem nego pojedine države. MNK se javljaju kao akteri odlučivanja i uticaja i u međunarodnim organizacijama. Kada se na međunarodnom forumu pregovora formulišu politike koje će se nakon usvajanja primenjivati na sve države potpisnice, tu takođe jak lobi imaju MNK. Njihov uticaj je jak i tamo gde nisu direktno vidljive, niti direktno učestvuju kao pregovarači. Sve je veći i interes ovih kompanija da utiču ne samo na lokalnom, nego i na državnom i međunarodnom nivou na definisanje politika zaštite životne sredine, telekomunikacija, savremenih tehnologija i svemu drugom u čemu mogu videti potencijalni profit. Na ovakav način ove kompanije šire svoj uticaj na sve veći broj polja života i rada. Postajući sve snažnije i ekonomski moćnije MNK šire svoj uticaj na političku, pravnu i druge sfere ljudskog delovanja. Uporedo sa jačanjem ekonomske moći razvija se i jača međunarodno pravni subjektivitet MNK.

\section{KRŠENJE MEĐUNARODNOG PRAVA OD STRANE MULTINACIONALNIH KOMPANIJA I OKVIR ZA NJIHOVU ODGOVORNOST}

S obzirom na to da je tradicionalni međunarodni okvir za zaštitu ljudskih prava orijentisan na kršenje istih od strane država, ono obavezuje prvenstveno države da obezbede zaštitu ljudskih prava. 
Međutim, sa širokim poljem delovanja MNK, u više država istovremeno, javlja se problem da države više ne drže monopol u kršenju, odnosno zaštiti ljudskih prava. ${ }^{13}$ Iako se u međunarodnoj zajednici sve više ističe ovaj nedostatak $\mathrm{u}$ regulativi, proširivanje obuhvata i dubine zaštite ljudskih prava i na MNK još uvek nije realizovano. Međunarodno pravo je ovde ispoljilo svoju neadekvatnost i značajno kašnjenje u rešavanju ovog problema.

Posmatrano s jedne strane, MNK mogu doprineti ekonomskom i tehnološkom razvoju zemlje domaćina, povećavajući bogatstvo i poboljšavajući uslove života. Zbog toga zaslužuju zaštitu i od prevelikog uplitanja vlade države domaćina, kao i obezbeđivanje od iste vlade stabilnog, predvidljivog poslovnog okruženja koji će im omogućiti strategijsko dugoročno planiranje rasta i razvoja. Međutim, posmatrano s druge strane, MNK mogu ozbiljno ugroziti ljudska prava i životnu sredinu u zemlji u kojoj posluju, a čak i počiniti teške zločine za koje bi trebalo da odgovaraju. Pojedinačno države najčešće nemaju dovoljno razrađenu regulativu da obuhvate i da gone ovakve slučajeve. ${ }^{14}$

Kako nam praksa pokazuje multinacionalne kompanije uspevaju da izmaknu regulisanju obaveza na državnom nivou, kao i kazni za kršenje lokalnih i nacionalnih propisa. Međutim, i regulativa na međunarodnom planu MNK je problematična.

Vođene su mnoge rasprave o međunarodnopravnom subjektivitetu MNK, međutim nije se suštinski raspravljalo, ili preciznije nije se dovoljno raspravljalo, o suštinskom pitanju prava i obaveza MNK po međunarodnom pravu.

Regulisanje prava i obaveza MNK je za sada jedino precizirano pod nacionalnim zakonima. Međutim, MNK već sada uživaju značajna prava prema međunarodnom investicionom pravu i prema međunarodnom pravu o zaštiti ljudskih prava. MNK mogu osigurati zaštitu svoje imovine pred domaćim sudovima i putem arbitražnih postupaka, kao i traženjem zaštite od kršenja njihovih prava pred Evropskim sudom za ljudska prava.

${ }^{13}$ Deva Surya, "Human rights violations by multinational corporations and international law: where from here", Conn. J. Int'1 L. 2003;19:1.

14 Jan Wouters, Chané 
Nasuprot ovim pravima, MNK nemaju propisanih obaveza prema međunarodnom pravu. Bez obzira na niz inicijativa u pokušaju da se stvore i dobrovoljni i obavezujući instrumenti, međunarodni zakon o ljudskim pravima još nije obuhvatio na zadovoljavajući način MNK. U najboljem, postoji određena odgovornost da se ne naudi ljudskim pravima, ali sprovođenje i primena ovih obaveza zavisi od odgovarajućih državnih organa. ${ }^{15}$ To dovodi do situacije u praksi, tamo gde država nije angažovana na zaštiti ljudskih prava ili na zaštiti životne sredine, na primer, da MNK rade po nahođenju i bez pravno obavezujuće odgovornosti.

Specijalni predstavnik Generalnog sekretara Ujedinjenih nacija za poslovanje i ljudska prava Džon Rugi (John Ruggie), objavio je okvir u kojem tvrdi da je ključna odgovornost korporacija poštovanje ljudskih prava. Specijalni predstavnik je takav okvir predstavio Savetu za ljudska prava u junu 2008. godine. Okvir "Zaštita, poštovanje i lek" (The "Protect, Respect and Remedy" Framework) počiva na tri stuba:

- dužnosti države da štiti od zloupotrebe ljudskih prava od strane trećih lica, uključujući tu i preduzeća, i to odgovarajućim politikama, regulativama i presudama;

- korporativnoj odgovornosti za poštovanje ljudskih prava, što znači da se postupa sa dužnom pažnjom kako bi se izbeglo kršenje prava drugih i rešavanje negativnih uticaja koji se javljaju; i

- većem pristupu žrtava efikasnom pravnom leku, kako sudskom tako i vansudskom.

Rugijev okvir pokrenuo je razvoj koji predviđa pojačanu odgovornost MNK bez umanjivanja primarne odgovornosti država. Da li će, ipak, ova inicijativa za pravno obavezujući instrument ljudskih prava uspeti da prevaziđe postojeće političke podele, ili će podeliti sudbinu ranijih pokušaja prelaska izvan dobrovoljnog okvira, još uvek ostaje da se vidi.

U radu Bilčiza (Bilchitz), koji analizira ovu tvrdnju u svetlu međunarodnog prava o ljudskim pravima, iznosi se stav da iako Rugieva koncepcija odgovornosti za efikasno poštovanje uključuje i odgovornost

${ }^{15}$ Ibid., p. 24. 
za zaštitu, priroda odgovornosti ostaje uglavnom „negativna“ po prirodi. Takođe se iznose tvrdnje da je Rugieva koncepcija prirode korporativnih obaveza pogrešna, jer od MNK ne treba tražiti samo da izbegavaju štetu osnovnim pravima, od njih se takođe mora tražiti da aktivno doprinose ostvarivanju takvih prava. Ovo razumevanje prirode korporativnih obaveza od posebnog je značaja za zemlje u razvoju i ilustrovano je razmatranjem dužnosti farmaceutskih kompanija da lekovi koji spasavaju život budu po pristupačnim cenama dostupni onima koji ih trebaju. ${ }^{16}$

\section{ELEMENTI MEĐUNARODNOPRAVNOG SUBJEKTIVITETA MULTINACIONALNIH KOMPANIJA}

Prema Mučlinskom (Muchlinski), bilo bi neprimereno prepuštanje pitanja ljudskih prava korporativnoj samoregulaciji i nerazumno dodeljivanje kompanijama uloge koju nisu u stanju da ispune. ${ }^{17}$ Kada govorimo o međunarodnopravnom subjektivitetu, onom koji je svojstven državama, jasno je da MNK nemaju sve elemente punog međunarodnopravnog subjektiviteta. Ipak, čak i ako nije potpun, prema Krivokapiću, njihov međunarodnopravni subjektivitet je nesumnjiv. ${ }^{18}$ Iz ugla međunarodnog prava, pojedine $\mathrm{MNK}$,imaju pravnu sposobnost (sposobnost da budu nosilac većeg ili manjeg kruga međunarodnim pravom utvrđenih prava i obaveza), poslovnu sposobnost (sposobnost zaključenja međunarodnih ugovora, stvaranja međunarodnopravnih običaja itd.), deliktnu sposobnost (sposobnost da se snosi predviđena pravna odgovornost zbog kršenja normi međunarodnog prava), procesnu sposobnost (aktivnu i pasivnu legitimaciju kod nekih međunarodnih sudova) itd“. ${ }^{19}$

${ }^{16}$ David Bilchitz, The Ruggie framework: An adequate rubric for corporate human rights obligations. SUR-Int'1 J. on Hum Rts. 2010;12:199.

${ }^{17}$ Peter Muchlinski, "Corporations in International Law", In Max Planck Encyclopaedia of Public International Law, Edited by Rudiger Wolfrum. Oxford: Oxford University Press, 2009.

${ }^{18}$ Boris Krivokapić, „Multinacionalne (transnacionalne) kompanije kao subjekti međunarodnog javnog prava“. Godisnjak Fakulteta Pravnih Nauka, 2017 Jul 1;7(7).

${ }^{19}$ Ibid., str. 110. 
Iako su države primarni kreatori međunarodnog prava, MNK imaju na raspolaganju različite načine za oblikovanje procesa donošenja zakona. One mogu doprineti radu ILO-a kroz mehanizam "tripartizma“ i baviti se svojim interesima u međunarodnoj investicionoj arbitraži ili preko država članica STO-a u mehanizmu za rešavanje sporova. Svojom političkom, socijalnom i ekonomskom moci mogu da utiču na zakonodavni proces lobiranjem na nacionalnom nivou dotične države članice, na nivou EU i na međunarodnom nivou, ili učešcem $u$ dijalogu i u konsultacijama. Međutim, sukobljeni ciljevi politike država ili međunarodnih organizacija, kao i aktivizam nevladinih organizacija mogu ograničiti uticaj $\mathrm{MNK}^{20}$

MNK „nemaju sposobnost da poseduju razne vidove međunarodne pravne nadležnosti (teritorijalna, personalna i u interesu međunarodne zajednice); nemaju sposobnost vođenja odbrambenog rata; nemaju sposobnost mirnog rešavanja međunarodnih sporova u užem smislu, odnosno učešća u tim procesima; nemaju aktivno i pasivno pravo poslanstva (sposobnost da se šalju i primaju diplomatski predstavnici); ne uživaju imunitet od strane jurisdikcije (kao što je to slučaj sa državama); nemaju sposobnost da kažnjavaju druge subjekte međunarodnog prava tj. da vrše kaznenu funkciju (jus punendi), u principu ne mogu biti članice međunarodnih (vladinih) organizacija itd“ ${ }^{21}$

Prava i obaveze MNK, kao i njihova odgovornost, nisu regulisane univerzalnom tj. globalnom poveljom ili ugovorom. MNK su potpisnice brojnih ugovora sa vladama država, posebno $u$ industrijama naoružanja, vazdušnog saobraćaja, telekomunikacija, finansija i bankarstva, kao i u uslužnim delatnostima konsaltinga. Ovi ugovori se mogu javiti i kao pravni izvori. MNK sve više učestvuju u javnoprivatnom partnerstu, izradi naručenih dokumenata, ekspertizama, konsaltingu, donacijama i drugo.

${ }^{20}$ Peter Muchlinski, "Multinational Enterprises as Actors in International Law: Creating "Soft Law" Obligations and "Hard Law" Rights" in Math Noortmann and Cedric Ryngaert (eds), Non-State Actor Dynamics in International Law: From Law-Takers to Law-Makers?, Ashgate 2010, p. 9.

${ }^{21}$ Krivokapić, op. cit., str. 124. 
Sporovi između MNK i država ponekad se poveravaju raznim međunarodnim arbitražama, koje postupaju na osnovu međunarodnog prava. MNK se mogu javiti kao parnične strane i pred Stalnim arbitražnim sudom koji je donedavno bio otvoren samo za države, kao i pred Međunarodnim sudom za pravo mora. Takođe, $u$ nekim slučajevima MNK su se pojavljivale kao strane $u$ postupku pred Evropskim sudom za ljudska prava. ${ }^{22}$

Pošto multinacionalna kompanija, posmatrana kao celina, nije isključivo vezana ni za jednu zemlju, Faturos (Fatouros) smatra da bi ga trebalo tretirati kao stranca u svim zemljama gde ima filijale, uključujući i zemlju gde je locirana matična kompanija. ${ }^{23}$

Promene $u$ globalnoj proizvodnji, pružanju usluga i trgovini su snažne i vidljive i one nameću dosta izazova međunarodnom regulatornom okviru. ${ }^{24}$ Štiglic je dao kritički osvrt na to kako bilateralni ugovori i trgovinski sporazumi favorizuju multinacionalne korporacije. ${ }^{25}$ Multinacionalne kompanije, kao veoma moćni učesnici u svetskoj privredi, imaju svoje interese i trude se da ih ostvare putem predlaganja i lobiranja za rešenja $u$ međunarodnom pravu koja njima odgovaraju. Izuzetno kritičnu analizu, koja tvrdi da MNK funkcioniše poput psihopatske ličnosti u potrazi za profitom i moci, dao je u svojoj analizi Bakan. ${ }^{26}$ Bez obzira na činjenicu da im fale svi elementi punog međunarodnopravnog subjektiviteta MNK su dovoljno moćne da svaki

${ }^{22}$ Ibid., str. 123.

${ }^{23}$ Fatouros. A. A., "Problemess et methodes d'une reglementation des enterprises multinationales", Journal du Droit International No 3, 1974, p. 507. citirano prema Miodrag Sukijasović, Multinacionalno preduzeće - pravni aspekti, Institut za međunarodnu politiku i privredu, Beograd 1981, str. 50.

${ }^{24}$ Sanja Jelisavac Trošić, "Challanges to Ensure that the Regulatory Framework Keeps Up with Changes in the Global Trade", in: Branislav Djordjevic, Taro Tsukimura, Ivona Ladjevac (eds.), Social and Economic Problems and Challenges in the Contemporary World, Global Resource Management, Doshisha University, Japan, Institute of International Politics and Economics, Belgrade, 2017, pp. 234-254.

${ }^{25}$ Joseph E Stiglitz, "Multinational Corporations: Balancing Rights and Responsibilities", Proceedings of the American Society of International Law 101 (2007): 3-60.

${ }^{26}$ Joel Bakan, The Corporation: The Pathological Pursuit of Profit and Power, New York: Free Press, 2004. 
potencijalni međunarodni regulatorni okvir podrede svojim interesima. Odgovornost, pre svega, svih država sveta a zatim i međunarodnih organizacija, pokreta, nevladinih organizacija, organizacija za zaštitu ljudskih prava, organizacija za zaštitu životne sredine i pojedinaca je u tome da se na međunarodnom, državnom, regionalnom, lokalnom i pojedinačnom nivou izbore za uspostavljanje pravnog sistema u kome će MNK imati pored prava i zakonske obaveze.

\section{ZAKLJUČAK}

Nakon što su u velikoj meri uklonjene trgovinske i investicione barijere, a troškovi prevoza i komunikacije opali, multinacionalne kompanije su postale generatori promena u globalnoj ekonomiji tokom poslednjih nekoliko decenija. U svetu globalnih lanaca vrednosti, velikih obima globalne proizvodnje i trgovine, bolje razumevanje MNK, njihovih ekonomskih karakteristika, pravne regulative, statističkog obuhvata, kako deluju, koji su im interesi, gde plaćaju porez i drugo, veoma je važno.

Multinacionalne kompanije već duži vremenski period imaju u svojim rukama ne samo ekonomsku moć već i političku da utiču, između ostalog, i na međunarodnu pravnu regulativu svoga poslovanja. Pozivi i potreba da se međunarodnim pravom regulišu prava, ali pre svega i obaveze MNK sve su prisutniji. Postoje izveštaji o umešanosti MNK u kršenju ljudskih prava, kao i izveštaji o zagađivanju životne sredine, pa je i snažna potreba da se one pozovu na odgovornost i pred međunarodnim pravom. Naravno, odgovornost i dalje treba da primarno ostane $u$ rukama pojedinačnih država, ali se određenim međunarodnim okvirom mogu pružiti smernice, posebno imajući u vidu da finansijska, politička i snaga lobiranja pojedinih MNK prevazilazi snagu velikog broja država sveta.

\section{LITERATURA}

Alvarez, José, 2010, “Are Corporations 'Subjects' of International Law?' NYU School of Law", Public Law Research Paper No. 10-77, Available at SSRN: http:/ / ssrn.com/abstract=1703465, 26.05.2020. 
Bakan, Joel, The Corporation: The Pathological Pursuit of Profit and Power. New York: Free Press, 2004.

Bilchitz, David, The Ruggie framework: An adequate rubric for corporate human rights obligations. SUR-Int'1 J. on Hum Rts.. 2010;12:199.

Bjelić, Predrag, Jelisavac Trošić, Sanja, Popović Petrović, Ivana, Savremena međunarodna trgovina, Institut za međunarodnu politiku i privredu, Beograd, 2010.

Deva, Surya, "Human rights violations by multinational corporations and international law: where from here", Conn. J. Int'1 L.. 2003;19:1.

Fatouros, A. A., "Problemess et methodes d'une reglementation des enterprises multinationales", Journal du Droit International No 3, 1974.

Jelisavac, Sanja, Intelektualna svojina - međunarodna trgovina pravima intelektualne svojine, Institut za međunarodnu politiku i privredu, Beograd, 2006.

Jelisavac, Trošić Sanja, "Challanges to Ensure that the Regulatory Framework Keeps Up with Changes in the Global Trade", in: Branislav Djordjevic, Taro Tsukimura, Ivona Ladjevac (eds.), Social and Economic Problems and Challenges in the Contemporary World, Global Resource Management, Doshisha University, Japan, Institute of International Politics and Economics, Belgrade, 2017, pp. 234-254.

Jelisavac Trošić Sanja, Pregovori u okviru GATT i STO, Institut za međunarodnu politiku i privredu, Beograd, 2015.

Krivokapić, Boris, „Multinacionalne (transnacionalne) kompanije kao subjekti međunarodnog javnog prava“", Godisnjak Fakulteta Pravnih Nauka, 2017 Jul 1;7(7).

Muchlinski, Peter, "Multinational Enterprises as Actors in International Law: Creating "Soft Law" Obligations and "Hard Law" Rights", in Math Noortmann and Cedric Ryngaert (eds), Non-State Actor Dynamics in International Law: From Law-Takers to Law-Makers?, Ashgate 2010.

Muchlinski, Peter, "Corporations in International Law", In Max Planck Encyclopaedia of Public International Law, Edited by Rudiger Wolfrum. Oxford: Oxford University Press, 2009. 
OECD, "Declaration on International Investment and Multinational Enterprises", https:/ / legalinstruments.oecd.org/en/instruments/ OECD-LEGAL-0144, 02.04.2020.

OECD, Baza ADIMA, https://www.oecd.org/sdd/its/measuringmultinational-enterprises.htm, 13.06.2020.

Sornarajah, Malanczuk, "Sources of international law in foreign investment" in The international law on foreign investment, Cambridge: Cambridge University Press, 2010, pp. 79-87.

Stiglitz, Joseph E., "Multinational Corporations: Balancing Rights and Responsibilities", Proceedings of the American Society of International Law 101 (2007): 3-60.

Sukijasović, Miodrag, Multinacionalno preduzeće - pravni aspekti, Institut za međunarodnu politiku i privredu, Beograd 1981, str. 47-48.

Wouters, Jan, Chané, Anna-Luise, "Multinational corporations in international law", KU Leuven Working Paper No. 129, Available at SSRN: https:/ / ssrn.com/abstract=2371216 or http://dx.doi.org/ 10.2139/ssrn.2371216. 


\section{MULTINATIONAL COMPANIES IN INTERNATIONAL LAW}

Abstract: In the world economy today, multinational companies (MNCs), which by their nature are created by pooling capital to make as much profit as possible, play an increasingly important role. When we talk about phenomena such as globalization and integration of business on the world market, they cannot be imagined without MNCs, which are both a consequence and a driver of these processes. These companies make big profits, and their business transcends national borders and national regulations. By their actions, MNCs bring complexity to the economic and legal relations and their regulations. Some MNCs appear in the world economy and international law as extremely powerful non-state actors. Given that some MNCs are even economically stronger than many countries in the world, they seek to obtain numerous concessions from countries through the establishment of mutual relations, as well as through other legal regulations. Also, in order to gain as much profit as possible, they direct and influence the work of international organizations. In that way, MNCs are currently one of the most powerful subjects of modern international economic relations, and they are trying to gain that position in the legal regulations as well. The aim of this paper is to analyze the position of MNCs in the international community and especially international law, but also the issue of international legal regulation of MNCs, the violations of international law and frameworks for their responsibility, as well as the elements of international legal subjectivity.

Keywords: multinational companies, transnational companies, international law, capital, violation of international law, human rights. 